\title{
Epidemiological study of two wheeler traffic accident victims in medicolegal autopsies
}

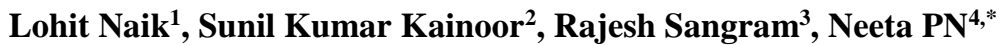 \\ ${ }^{\mathbf{1}}$ Assistant Professor, Travancore Medical College, Kollam, Kerala, ${ }^{2}$ Assistant Professor, ${ }^{3}$ Professor \& HOD, Dept. of Forensic \\ Medicine, Raichur Institute of Medical Sciences, Raichur, Karnataka, ${ }^{4}$ Assistant Professor, Dept. of Community Medicine, \\ VIMS, Ballari
}

*Corresponding Author:

Email: drnita10@gmail.com, drlohit16@gmail.com

\begin{abstract}
Background: Every year almost 1.3 million people lose their lives as a result of road traffic accidents, contributing to above 3500 deaths per day world-wide. The aim of this study was to assess the frequency and distribution of two wheeler accidents leading to fatality.

Material \& Methods: This was observational cross-sectional study of autopsies performed at the mortuary of Raichur institute of medical sciences, Raichur from January 2016 to December 2016. Data was collected on a proforma. The results were analyzed using Statistical Software Package SPSS version 20.

Results: Out of 565 autopsies, 104 cases were victims of two wheeler traffic accidents. Of these RTA victims, $30 \%$ autopsies were of those between the ages of 20 and 29 years. The gender distribution revealed a higher prevalence for males (59\%) than females (41\%). The majority of victims was from urban areas (50\%) and was employed group (28\%).

Conclusion: There was a higher preponderance for males, uneducated and in a young age group.
\end{abstract}

Keywords: Two wheeler accident, Road traffic accident, Raichur

\section{Introduction}

India is undergoing major economic and demographic transition coupled with increasing urbanization and motorization, it is projected that road traffic accidents will occupy as one of the major causes of mortality. Worldwide, every day about 3400 people die due to road traffic accidents (RTA) and predicted to result in death of around 1.9 million people annually by $2020 .{ }^{(1)}$ Nearly $90 \%$ of world's RTA fatalities are occurring in low and middle-income countries, whereas highly motorised countries contribute very little though they accommodate over $60 \%$ of world's vehicles. ${ }^{(2)}$ Road traffic accident is the most common cause of death in developing countries. Currently two wheelers are major component of road traffic, preferred family vehicle and they have taken mega share of road accidents. Motorcycle users, pedestrians and pedal cyclists are vulnerable road users who are directly exposed to impacting vehicle or hard objects during collision and likely to get injured severely. Even though two-wheeler related RTA deaths are very familiar on Raichur district roads, they are seemed to have been overlooked. Hence this study is aimed at interpreting epidemiological factors, frequency and distribution leading to fatality in two wheeler accidental deaths.

\section{Materials and Methods}

This study was conducted at the Raichur institute of medical sciences, Raichur from 1st January to 31st December 2016. Among the medico-legal autopsies conducted in the study centre, all two wheeler (motorized and non-motorized) related accidental deaths were included in this observational, cross section study. Data of demographic, characteristics and epidemiological factors behind every subject died in two wheeler accident were collected by personal interview with the concerned police authorities, relatives of the deceased, eye witnesses and survivors in the same accident. This was further evaluated to understand the human, vehicle and road factors in causing accidents. All body findings including injuries were personally examined at autopsy and correlated with the history. RTA deaths involving other than two wheeler vehicles, non-vehicular accidents \& injuries and non-confirmed cases are excluded.

\section{Statistical Methodology}

The results were analyzed using Statistical Software Package SPSS version 20. Statistical analysis was done for frequencies, percentages, proportions \& ratios and results were interpreted.

\section{Results}

Overall, 565 medico-legal autopsies were conducted in the study centre during calendar year 2016, among them 275 are RTA cases and 104 cases are purely two wheeler related RTA deaths. Two wheeler fatalities were significantly higher in males $(59 \%)$ than females $(41 \%)$. More victims were in the age group of 20 to 29 years (30\%) The majority of the victims belong to Urban population (50\%), Uneducated(40\%), Employed and business group $(28 \%)$. Fatal accidents happened more on national highways (39\%) and less on village roads $(11 \%)$. The geared motorcycles $(60 \%)$ were commonly involved in fatal accident than other motorcycles. 
Table 1: Age and gender wise distribution of cases

\begin{tabular}{|l|c|c|}
\hline \multicolumn{1}{|c|}{ Age group (yrs) } & Male & Female \\
\hline $0-9 y r s$ & $2(2 \%)$ & $1(3 \%)$ \\
\hline $10-19 y r s$ & $7(7 \%)$ & $5(5 \%)$ \\
\hline $20-29 y r s$ & $18(17 \%)$ & $14(13 \%)$ \\
\hline $30-39 y r s$ & $14(13 \%)$ & $11(10 \%)$ \\
\hline $40-49 y r s$ & $10(10 \%)$ & $4(4 \%)$ \\
\hline $50-59 y r s$ & $7(7 \%)$ & $6(6 \%)$ \\
\hline$>60 y r s$ & $3(3 \%)$ & $2(2 \%)$ \\
\hline Total & $\mathbf{6 1}(\mathbf{5 9 \%})$ & $\mathbf{4 3}(\mathbf{4 1 \%})$ \\
\hline
\end{tabular}

Table 1 show the age and sex distribution of cases. It shows that frequency of two wheeler accidents was more in Males $(51 \%)$ and common in 20-29 (31\%) yrs age group.

Table 2: Domicile distribution of cases

\begin{tabular}{|l|c|}
\hline \multicolumn{1}{|c|}{ Domicile } & Cases \\
\hline Rural & $24(23 \%)$ \\
\hline Semi urban & $25(24 \%)$ \\
\hline Urban & $52(50 \%)$ \\
\hline Unknown & $3(3 \%)$ \\
\hline Total & $\mathbf{1 0 4}$ \\
\hline
\end{tabular}

Table 2 shows the place of occurrence. It shows that frequency of two wheeler accidents was more in urban areas $(50 \%)$ in the rural areas $(23 \%)$ than semi urban $(24 \%)$.

Table 3: Educational status of cases

\begin{tabular}{|l|c|}
\hline \multicolumn{1}{|c|}{ Educational status } & Cases \\
\hline Uneducated & $42(40 \%)$ \\
\hline Primary school & $21(20 \%)$ \\
\hline Secondary \& Intermediate & $16(15 \%)$ \\
\hline Graduate \& above & $23(23 \%)$ \\
\hline Unknown & $2(2 \%)$ \\
\hline Total & 104 \\
\hline
\end{tabular}

Table 3 shows the educational status of the victims. It shows that most of the victims were uneducated $(24 \%)$.

Table 4: Occupational status of cases

\begin{tabular}{|l|c|}
\hline \multicolumn{1}{|c|}{ Occupational status } & Cases \\
\hline Unemployed & $16(15 \%)$ \\
\hline Employed \& Buisness & $29(26 \%)$ \\
\hline Students & $26(25 \%)$ \\
\hline Housewife & $17(16 \%)$ \\
\hline Agriculture \& Labour & $16(16 \%)$ \\
\hline Total & $\mathbf{1 0 4}$ \\
\hline
\end{tabular}

Table 4 shows the occupational status of the victims.It shows that frequency of frequency of two wheeler accidents was more in employed victims (26\%) than unemployed victims (15\%).
Table 5: Type of roads

\begin{tabular}{|l|c|}
\hline \multicolumn{1}{|c|}{ Type of road } & Cases \\
\hline National highway & $41(39 \%)$ \\
\hline State highway & $31(31 \%)$ \\
\hline City road & $15(14 \%)$ \\
\hline Village road & $12(11 \%)$ \\
\hline Unknown & $5(5 \%)$ \\
\hline Total & $\mathbf{1 0 4}$ \\
\hline
\end{tabular}

Table 5 shows the type of road where accident took place which was more in national highway (39\%).

Table 6: Two wheeler invoved

\begin{tabular}{|l|c|}
\hline \multicolumn{1}{|c|}{ Type of two wheeler } & Cases \\
\hline Geared motorcycle & $62(60 \%)$ \\
\hline Scooter & $24(23 \%)$ \\
\hline Pedal cycle & $10(10 \%)$ \\
\hline Unknown & $8(7 \%)$ \\
\hline Total & $\mathbf{1 0 4}$ \\
\hline
\end{tabular}

Table 6 shows that the geared motorcycles $(60 \%)$ were commonly involved in fatal accidents.

\section{Discussion}

Two wheelers are preferred transportation vehicles for vast Indian families as they are cheaper, gives better mileage, carry at least 2 to 3 passengers, easy to park $\&$ ride in traffic congestion. Two wheeler accidents are contributed for nearly half of total RTA deaths, two wheeler users and pedestrians have the highest rates of fatal injuries. ${ }^{(3,4)}$ The several factors blameworthy for high two wheeler accident are more vehicles on Indian traffic, Vehicle vulnerability, poor road status, coupled with non-adherence of riders to road safety rules \& traffic laws.

Males spend lots of their time in travelling and various outdoor activities, so they are prone to accidents and having unfavourable gender ratio. ${ }^{(5)}$

Individuals between 20 to 29 years of age are commonly involved in fatal RTA and hail from urban domicile. Earlier studies also reported that most victims were males in the age group of 20-49 years ${ }^{(6,7)} 18-37$ years ${ }^{(8)}$ and $18-44$ years. ${ }^{(9)}$ These people are more likely to expose who travel lot and are involved in the financial responsibility of the family.

Greater proportion of victims in two wheeler RTA is illiterates and low education personals and it may be correlated with poor road sense / Ignorance of road safety rules and traffic sense. ${ }^{(6,10)}$

The reasons for high incidence of accidents on the highways (National \& State) and city roads might be these roads are busiest, very narrow, too much traffic during peak hours, no traffic signals at junctions and no strict enforcement of road safety rules. Multifactorial involvement in accident outcome are such as the severity of accident, transportation problems, lack of medical emergency services, insufficient \& untrained staff and facilities in the hospitals. Hence the timely availability of quality emergency medical services to 
the injured will play a crucial role in preventing mortalities and disabilities. Too many factors (human, vehicular and roadways) contribute for causation of two wheeler accidents, and human errors are responsible for many fatalities. Though certainly knowing the fact that helmets reduce head, facial and brain injuries significantly, still most of the motorcycle occupants were found not-worn helmet at the time of accident. Driving a vehicle under intoxication is a crime, because alcohol intoxication impairs driving ability of a person and level of impairment is directly related to blood alcohol concentration. ${ }^{(11)}$ Use of mobile phones while driving a vehicle is associated with a high chance of accidents and hence traffic laws prohibit the use of these gadgets by the rider while driving. Many countries have imposed restrictions on the high speeding, legal age for driving license, graduate driver licensing, increase in fine \& withdrawal of Driver's license and speed control interventions have led to significant reduction in traffic accidents. ${ }^{(12)}$

\section{Conclusion}

Fatalities are remarkably high in motorized two wheeler accidents and most victims are males and young adults. Enhanced awareness and education to the general public and vulnerable road users on obeying traffic rules, use of road safety and protective measures while driving will mitigate accidents. Availability of excellent emergency trauma care centres \& ambulance services during the early hours of trauma in rural India will dramatically reduce mortalities and disabilities. Though multiple factors interacted in causation of RTA, they can be prevented to certain extent by implementing and enforcing traffic laws strictly such as drunken driving, crash helmets, mobile usage, and speed limit.

\section{References}

1. World Health Organization. Road Traffic Injuries Fact Sheet N0 358, March 2013. Available from: http://www.who.int/mediacentre/factsheets/fs358/en/ (accessed on 19 Jan 2015).

2. Peden M, Scurfield R, Sleet D, Mohan D, Hyder AA, Jarawan E, et al. The World report on road traffic injury prevention. Geneva. World Health Organization 2004.

3. Dandona R, Mishra A. Deaths due to road traffic crashes in Hyderabad city in India: Need for strengthening Surveillance. Natl Med J India 2004;17:74-9.

4. 4.Pathak A, Desania NL, Verma R. Profile of Road Traffic Accidents \& head injuries in Jaipur, JIAFM 2008;30(1):6-10.

5. Kochar A, Sharma GK, Murari A. Road Traffic Accidents and Alcohol: A prospective study. International J Medical Toxicol. Leg Med 2002;5:22-4.

6. Jha N, Srinivas DK, Roy G, Jagadish S. Epidemiological study of road traffic cases: A study from south India. Indian Journal of Community Medicine 2004;29:20-4.

7. Menon A, Pai VK, Rajeev A. Pattern of fatal head injuries due to vehicular accidents in Mangalore. Journal Forensic \& Legal Medicine 2008;15:75-7.

8. Ganveer GB, Tiwari RR. Injury pattern among non-fatal road traffic accidents cases: a cross sectional study in central India. Indian J Med Sci 2005;59(1):9-12.
9. Jain A, Kanchan T, Gagan S, Jain R. Two wheeler accidents on Indian roads- A study from Mangalore, India. Journal of Forensic \& Legal Medicine, April 2009;16(3):130-3.

10. Singh YN, Bairagi KK, Das KC. An epidemiological study of road traffic accident victims in medico-legal autopsies. JIAFM 2005;27(1):166-9.

11. Garbarino S, Nobili L, Beelke M. The contributing role of sleepiness in highway vehicle accidents. Sleep 2001;24:203-6.

12. Khambete AK. Epidemiology of Road Traffic Accidents in India: a review of Literature. Sir rattan Tata Trust 2011:1-100. 